\title{
Entrepreneurial attitude and business success
}

\section{Tsige Gebremeskel ${ }^{1}$}

\begin{abstract}
This study was carried out to observe the relationship between entrepreneurial attitude (that is measured through achievement and innovation) and success in business (as rated by the respondents). It also aimed at finding out if each of these two variables is affected by gender. To respond to these queries, the study addressed decisionmakers in pharmaceutical outlets. A set of questionnaire was distributed to 131 respondents and 56 of them were analyzed using correlations coefficient, percentages and t-tests. The major findings were: there is moderate relationship between entrepreneurial attitude and business success; there are gender differences when attitude is measured through achievement-affect; and all respondents have low scores when attitude is measured through innovation-behaviour. Based on the findings, the writer has made some recommendations.
\end{abstract}

\section{Introduction}

Ethiopia, to cope up with the business challenges and benefit from globalization, needs to emerge with better economy. The development of its economy presupposes entrepreneurial direction, which is believed to lead to improved social life and welfare. This means that Ethiopian trade and economic development should be marked by innovation, transformation, ambition, planned and intentional behaviour, and independence. Ethiopian business men and women should take intelligent risks that are knowledge-based and pave ways for new challenges and opportunities. Such a strategy helps Ethiopian entrepreneurship to grow.

This study, was geared towards finding out the relationship between entrepreneurial attitude and business success. In addition, it attempted to investigate how these two constructs were affected by gender.

\footnotetext{
${ }^{1}$ Assistant Professor, Addis Ababa University, College of Commerce.
} 
Entrepreneurship was measured against two components namely, achievement and innovation. The tripartite (ABC) model of attitude was employed and each variable of achievement and innovation was measured by affect, behaviour and cognition. Business success was measured through the respondents' rating their business compared to other similar ones and labelling it as 'very good' ( $\geq 75 \%)$, 'good' (50-74\%), 'low' (40-49\%), and 'bad' $(<40 \%)$. This variable was also observed against gender. Privately owned pharmaceutical retail outlets in Addis Ababa were the subject of this study.

\section{Objectives of the study}

Decision-makers of any business venture need to have entrepreneurial attitude, which is marked by innovativeness and achievement-orientation. This partly guarantees their success in holding better market share and customer satisfaction in their products and services. In addition, in both developed and developing nations, there are stereotypical differences in the jobs people hold and are assumed to hold. Some jobs are considered to be of females and others of males. Mueller (2004:3), who studied gender gaps in entrepreneurship, says "Gender stereotyping justifies the assignment of men and women to different occupational roles." Williams and Best's study was quoted in Mueller (2004) to have found out that gender stereotyping is common across cultures but it tended to be greater in less developing countries than in developed ones. Entrepreneurship, as discussed by Habtamu (1995) to have values of selfconfidence, self-reliance, courageousness, risk-taking and actionorientation, is assumed to be of masculine than feminine in many cultures.

This study thus aimed at:

- observing if there is a relationship between the entrepreneurial attitude the managers of the pharmaceutical outlets hold and the success in their business,

- exploring if entrepreneurial attitude among managers of pharmaceutical outlets differ by gender, 
$\Rightarrow$ gender differences on overall attitude and the two qualifying components, i.e. achievement and innovation.

$\Rightarrow$ gender differences across the $\mathrm{ABC}$ of entrepreneurial attitude, i.e. affect, behaviour (conation) and cognition. These lead to six subcategories, which are achievement-affect, achievement-behaviour, achievement-cognition, innovation-affect, innovation-behaviour, and innovation-cognition.

- observing the business success vis-a-vis gender.

\section{Research questions}

The study raises and examines the following questions:

- Are the entrepreneurial attitudes the decision-makers hold related to the business success of the outlets?

- Are the entrepreneurial attitudes that are held by male managers different from female managers?

- Is the business success of the respondents different between female and male decision-makers?

\section{Significance of the study}

As the number of pharmaceutical outlets is rapidly growing within Addis Ababa, the situation is believed to bring competitive atmosphere among them. This in turn presupposes continuous improvement which should be marked by entrepreneurial attitude that involves characteristics like innovativeness, risk taking behaviour, achievement, personal-control, self-esteem, and opportunity recognition (Lindsay, 2005).

Hence, this study is of importance to:

- policy makers who involve themselves in health-related matters for it is informative of what is going on in the pharmaceutical outlets in Addis Ababa,

- educational and training institutions that need to impart knowledge on entrepreneurship and related issues, 
- pharmaceutical outlets, businesswomen and businessmen as the study offers information on the importance of having entrepreneurial attitude, and

- academics and researchers in the area.

\section{Review of related literature}

\section{Operational definition of terms}

This section offers definition of relevant concepts:

- Gender: the social, economic, and cultural roles and relations between men and women

- Attitude: tendency to respond favourably or unfavourably to entrepreneurial characteristics with particular emphasis on achievement and innovativeness

- Entrepreneurship: creation and production of new ways of doing things

- Pharmaceutical outlets: privately owned large and small scale sellers of pharmaceutical items

- Managers: owner or employed persons who are responsible in making decisions relating to the pharmaceutical outlets

\section{Entrepreneurship and business success}

CAFRAD (2000:3) stated that "A society without entrepreneurship is a dead society. Without ... entrepreneurship, no growth and no progress can be expected. Entrepreneurship creates jobs, leads to new knowledge and new competence."

According to Mueller (2004), on the other hand, the formation of entrepreneurial intentions depends on personal attitude. ReimersHild et al (2005:1), also argued, “... entrepreneurial behaviour is a vital asset in the rapidly changing global knowledge economy of the 21st Century. ...entrepreneurs ..... seek out and capitalize on 
opportunities and marshal resources to achieve their goals. ... [There is] a relationship between the entrepreneurial personality, which is the combined score of locus of control, need for achievement and risk taking propensity, with success and persistence ...." Bradstatter (1997) described 'entrepreneurial behaviour', as characteristics like taking initiative, being innovative, shaping the environment according to one's ideas and goals to qualify entrepreneurial behaviour. Mueller (2004) also said that people's entrepreneurial activity represents a planned and therefore intentional behaviour.

In another study, Mueller and Thomas, as quoted in Mueller (2004), did a comprehensive multinational study and found that the prevalence of an entrepreneurial orientation is higher in some cultures than in others. They also found out that the frequency of entrepreneurial traits such as internal locus of control, risk-taking propensity, and high energy decreased as the cultural distance from the United States increased.

\section{Entrepreneurial innovation and success}

Reimers-Hild et al (2005) described successful entrepreneurs as innovative individuals.

CAFRAD (2000) added that innovation works along with entrepreneurship, and that there is no successful entrepreneurship without innovation. Mueller (2004) stated innovativeness as an important element of entrepreneurship. Lindsay (2005) explained innovation as involving, in perceiving and acting upon business activities in new and unique ways.

Mueller (2004) said that some societies appear more innovative than others. In addition, Shane quoted in Mueller (2004) found out that higher rates of innovation are associated with national cultural values of uncertainty, acceptance, power distance, and individualism. In relation to this, Lindsay (2005:9) said that ".... cultural influences will restrict innovation to developing and acting upon new and unique business activities that only conform to cultural norms. Any business innovation contemplated outside cultural norms will not feature strongly in indigenous thinking. As such, indigenous entrepreneurial attitudes toward innovation will be restricted and will be low." 


\section{Entrepreneurial achievement}

Reimers-Hild et al. (2005:3-4) said "High need for achievement ( $n$ Ach) is a key entrepreneurial trait and recognized leadership characteristics of entrepreneurs. High $n$ Ach is also associated with entrepreneurial leadership and entrepreneurial behaviour. High achieving individuals are characterized by self-confidence, the ability to take calculated risks, the skill to research their environment and the desire for feedback about their performance. Johnson quoted in Koh (1996) said that there is a fairly consistent relationship between need for achievement and entrepreneurship. According to Lindsay (2005), achievement is associated with business start-up and growth results as need for achievement appears to be an important characteristic of entrepreneurial personality.

\section{Gender differences in entrepreneurship and business success}

Research findings on gender differences in entrepreneurship show inconsistent results. For example, James et al (2004) took 700 college presidents to see if there are gender differences in entrepreneurial leadership. They found out that the female presidents are more transformational, taking calculated and measured risks that could possibly cost their jobs, innovative in looking outside the box, befriended and tolerant to unusual individuals and change, and improvement oriented, than their male counterparts.

Routamaa et al (2004) tried to observe gender differences in entrepreneurial attitude and found women to have slightly more positive attitudes towards entrepreneurship. Shane, Kovereid and Westhead, quoted in Routamaa et al (2004) found male entrepreneurs to be more motivated by need to improve their positions in society, while female entrepreneurs to be more motivated by the need for achievement. Moreover, they quoted Wasilczuk, who found women to be more persistent than men but less inclined to take risks and less ready to be committed to the firm. In another study, Mueller (2004) quoted authors who 
studied gender differences in entrepreneurship. In Mueller's (ibid) review, Mathews and Moser found males having higher levels of interest than females in small business ownership. According to Scherer, Brodzinske and Wiebe reached, males have a higher preference for entrepreneurship than females; and Sexton and Bowman-Upton however, found no significant difference on five of the nine traits they measured, with exceptions of female respondents scoring lower on traits related to energy level and risk taking behaviour and higher on traits related to autonomy and change.

Brandstatter (1997) quoted Cromie who studied entrepreneurship through autonomy and achievement and who used a sample of 35 male and 34 female business owners. The findings showed no differences on questionnaire scores between the sexes. Similarly, Bonnett and Furnham in Brandstatter (1997) compared boys and girls (aged 16 to 19) who participated in Young Enterprise scheme. Their results showed no difference between the sexes. In addition, Gatewood et al., in Brandstatter 1997, found women's entrepreneurial success to be related to stable internal feelings like "I have always wanted to own my own business" while men's entrepreneurial success to be related to stable external attribute like "I had identified a market need." Brandstatter (1997), on the other hand, took 500 respondents (out of whom 98 were female) and found no differences between males and females on their personality that is related to entrepreneurial roles (emotional stability and independence). So, the reviewed literature showed both the prevalence and the non-prevalence of gender differences on entrepreneurship.

\section{Methodology}

Sampling: This study focused on privately owned pharmaceutical retail outlets that are found in Addis Ababa. According to Ministry of Health (MOH) (2004), there are 205 privately owned pharmaceutical retail outlets (104 pharmacies, 95 drug stores and 6 rural drug vendors) in Addis Ababa. The sampling technique employed in this study was non-random convenience sampling because the total population was relatively small. The respondents of this study were only those who were willing to fill out the questionnaire. 
Data collection method: The instrument used to collect data was questionnaire. The questionnaire involved six demographic and social variables: sub-cities in Addis Ababa, responsibility in the organization, gender, age, capital, and type of business. The core items in the questionnaire were adopted from Robinson et al. (1991) Entrepreneurial Attitude Orientation (EAO) scale that involved four sub-categories achievement, innovation, personalcontrol and self-esteem.

In giving explanation to measuring entrepreneurial attitude, Robinson et al (1991:18) said: "One of the methodological advantages of the attitude model over the personality model is that it can be more domain-specific, thereby reducing the unexplained variability and increasing the correlations with behaviour." For this reason, they came up with three factors that can measure entrepreneurship which they called the tripartite model. Robinson et al. (1991:17) stated: “... the tripartite model holds that there are three types of reaction to everything: affect, cognition, and conation. Attitude is a combination of all three.... The cognitive component consists of the beliefs and thoughts an individual has about an attitude object. The affective component consists of positive or negative feelings toward the object. The conative or behavioural component consists of behavioural intentions and predispositions to behave in a given way toward the object."

The adopted questionnaire originally involved 75 items. But in this study, it was brought down to 28 items by taking only two sub-categories, achievement and innovation. The underlying reasons are as follows: First, in measuring entrepreneurship, these two elements, innovation (creativity) (Lindsay, 2005; ReumersHild et. al, 2005; CAFRAD, 2000) and achievement (ReumersHild et al, 2005; Lindsay, 2005) have been commonly used. Secondly, the writer wanted to minimize response bias by limiting the number of items and avoid respondents' boredom of filling out long list of items.

The questionnaire had Amharic and English versions so that respondents would fill it out in the language they felt more comfortable. 


\section{The following table shows item distribution in the questionnaire}

\begin{tabular}{|l|r|r|}
\hline \multicolumn{1}{|c|}{ Category } & \multicolumn{1}{c|}{ Items } & No. of items \\
\hline Achievement - Affect & $1,13,17,27$ & 4 \\
\hline Achievement - Behaviour & $3,7,8,12,20,25$ & 6 \\
\hline Achievement - Cognition & $5,9,14,18,19$ & 5 \\
\hline Innovation - Affect & $4,10,15,22,26$ & 5 \\
\hline Innovation - Behaviour & $2,11,23,28$ & 4 \\
\hline Innovation - Cognition & $6,16,21,24$ & 4 \\
\hline
\end{tabular}

In the pharmaceutical outlets, decision makers (they could be the owners themselves or employed managers) were contacted to fill out the questionnaire. Out of the 131 copies of questionnaire distributed, only 60 were returned. Four were, discarded for they were inappropriately completed. The balance (i.e., 56 copies of questionnaire) was used for analysis.

\section{Data analysis methods}

Pearson's correlation research method was used to observe the relationship between overall attitude score and the success of the business as reported by the respondents. However, as the number of copies of the questionnaire received was limited, descriptive statistics mainly percentage was employed to analyse the data in observing gender differences. To be able to cross tabulate the data, the scores for the overall entrepreneurial attitude, the accompanying two categories (achievement and innovation), and the six sub-categories under them were recoded into 'low' and 'high.' Let us take the achievement variable as an example so as to elaborate the recoding. Out of the 28 core items, 15 measure achievement. The minimum score that shows achievement in entrepreneurship is 60 (which is $4 \times 15$ ), where 4 represents 'agree'. On the other hand, the maximum score is 75 ( $5 \times 15)$, where 5 represents 'strongly agree'. Therefore, those who score in the range of $60-75$ have high and positive attitude towards entrepreneurship as measured by achievement, and hence are categorized as 'high' while the rest whose scores were below 60 were categorized as having 'low' entrepreneurial attitude as measured by achievement. 
Out of the 56 respondents, 29 were male while 21 were female; hence six cases were missing from gender analysis due to the uneven gender representation. This made the data not to assume normal distribution and made it difficult to use z-statistics to show difference of means between the sexes. For this reason, the researcher used t-tests that enabled comparison of means. In this study, the computer package used to process the data was SPSS.

\section{Findings}

The respondents of this study were decision makers in different pharmaceutical outlets in Addis Ababa. The questionnaire used to collect the data involved six demographic and social variables that are described below.

Table 1: Respondents' profile by gender and age

\begin{tabular}{|l|r|r|r|r|r|c|}
\hline & \multicolumn{7}{|c|}{ Age } \\
\hline Gender & $20-29$ & $30-39$ & $40-49$ & $50-59$ & $>=60$ & Total \\
\hline Male & 5 & 13 & 9 & 1 & 1 & $29(58.0)$ \\
\hline Female & 7 & 9 & 5 & - & - & $21(42.0)$ \\
\hline Total & $12(24.0)$ & $22(44.0)$ & $14(28.0)$ & $1(2.0)$ & $1(2.0)$ & $50(100)^{*}$ \\
\hline
\end{tabular}

Source: Survey data

* Numbers in parenthesis are percentages.

Table 1 above shows that apart from six missing cases, $42 \%$ of the respondents in this study were females while $58 \%$ were males. 
Table 2: Respondents' profile by type of outlet and amount of capital

\begin{tabular}{|l|r|r|r|r|}
\hline & \multicolumn{4}{|c|}{ Type of Outlet } \\
\hline \multicolumn{1}{|c|}{ Capital } & $\begin{array}{c}\text { Pharmac } \\
\text { y }\end{array}$ & $\begin{array}{c}\text { Drug } \\
\text { store }\end{array}$ & $\begin{array}{c}\text { Importer } \\
\text { /distributor }\end{array}$ & Total \\
\hline$<20,000$ & 3 & 2 & - & $5(10.9)$ \\
\hline $20,000-500,000$ & 31 & 2 & 1 & $34(74.9)$ \\
\hline$>500,000$ & 4 & 1 & 2 & $7(15.2)$ \\
\hline Total & $38(82.6)$ & $5(10.9)$ & $3(6.5)$ & $46(100)^{*}$ \\
\hline
\end{tabular}

Source: Survey data

* Numbers in parenthesis are percentages.

As can be observed in Table 2 above, valid cases for variables that state type of outlet and amount of capital of the establishment indicate that $82.6 \%$ are in the business of pharmacy, $10.9 \%$ in drug store, and $6.5 \%$ importers and distributors of pharmaceuticals. In relation to this, out of the sample population, $14.9 \%$ were reported to have been owners of the outlets, $55.3 \%$ were employed managers while $29.8 \%$ were both owners and managers. The respondents were found scattered in all the ten sub-cities of Addis Ababa where the dominant distribution i.e. $25.5 \%$ goes to Bole, $17.6 \%$ to Lideta, $15.7 \%$ to Kirkos, and $13.7 \%$ to Addis Ketema sub-cities.

\section{The relationship between entrepreneurial attitude and business success}

In this sub-section, correlation research was employed to see if entrepreneurial attitude and success in a person's business venture are related. The result of coefficient of correlation was found to be $r=0.24$, with $p$ value of 0.088 . This correlation shows that there is moderate relationship between the two variables. So, this study shows that entrepreneurial attitude and success in business go along where the higher entrepreneurial attitude one has, the better he/she is in achieving success in their business, and viceversa. 
Gender differences and entrepreneurial attitude

1. Gender differences and overall entrepreneurial attitude

Table 3: Gender and overall entrepreneurial attitude score

\begin{tabular}{|l|r|r|r|r|r|r|}
\hline \multirow{2}{*}{$\begin{array}{l}\text { Overall } \\
\text { score }\end{array}$} & \multicolumn{2}{|c|}{ Male } & \multicolumn{2}{c|}{ Female } & \multicolumn{2}{c|}{ Total } \\
\cline { 2 - 7 } & Size & Percent & Size & $\begin{array}{c}\text { Percen } \\
\text { t }\end{array}$ & Size & Percent \\
\hline Low & 12 & 41.4 & 6 & 28.6 & $\mathbf{1 8}$ & $\mathbf{3 6}$ \\
\hline High & 17 & 58.6 & 15 & 71.4 & $\mathbf{3 2}$ & $\mathbf{6 4}$ \\
\hline Total & $\mathbf{2 9}$ & $\mathbf{5 8}$ & $\mathbf{2 1}$ & $\mathbf{4 2}$ & $\mathbf{5 0}$ & $\mathbf{1 0 0}$ \\
\hline
\end{tabular}

Source: Survey data

As shown in the above table, the proportional comparison of the respondents by gender over their entrepreneurial attitude shows that $58.6 \%$ of the male respondents and $71.4 \%$ of the female respondents scored high on the target variable. Conversely, $41.43 \%$ of males and $28.6 \%$ of females scored low. These percentages show that females have higher entrepreneurial attitude compared to males. To observe if this difference has statistical significance, t-test was run as shown below.

Table 4: Gender differences and overall entrepreneurial attitude

\begin{tabular}{|c|c|c|c|r|}
\hline $\begin{array}{c}\text { Mean of } \\
\text { males }\end{array}$ & $\begin{array}{c}\text { Mean of } \\
\text { females }\end{array}$ & $\begin{array}{c}\text { Mean } \\
\text { difference }\end{array}$ & t-value & p-value \\
\hline 114.4483 & 116.6190 & -2.1708 & -0.78 & 0.438 \\
\hline
\end{tabular}

$\mathrm{t}_{(0.05 ; 1,48)}=2.0106$

\section{Source: Survey data}

The result shows that there is no statistically significant difference between male and female respondents of this study on their entrepreneurial attitude. 
2. Gender differences and the two categories of entrepreneurship (achievement and innovation)
A) Gender differences and achievement score

Table 5: Cross tabulation of achievement scores by gender

\begin{tabular}{|l|r|r|r|r|r|r|}
\hline \multirow{2}{*}{$\begin{array}{l}\text { Achievement } \\
\text { score }\end{array}$} & \multicolumn{2}{|c|}{ Male } & \multicolumn{2}{c|}{ Female } & \multicolumn{2}{|c|}{ Total } \\
\cline { 2 - 7 } & Size & Percent & Size & Percent & Size & Percent \\
\hline Low & 7 & 24.1 & 0 & -- & $\mathbf{7}$ & $\mathbf{1 4}$ \\
\hline High & 22 & 75.9 & 21 & 100 & $\mathbf{4 3}$ & $\mathbf{8 6}$ \\
\hline Total & $\mathbf{2 9}$ & $\mathbf{5 8}$ & $\mathbf{2 1}$ & $\mathbf{4 2}$ & $\mathbf{5 0}$ & $\mathbf{1 0 0}$ \\
\hline
\end{tabular}

\section{Source: Survey data}

When gender differences for this variable are proportionally observed, $100 \%$ of the female respondents have high scores on entrepreneurial attitude as measured by achievement. From the male respondents, $75.9 \%$ have high scores on entrepreneurial attitude as measured by achievement while $24.1 \%$ scored low. This result shows that female respondents of this study have high achievement-orientation compared to their male counterparts. The statistical significance of this difference was observed by a t-test; where mean difference between males and females is -2.1 , t-value is -1.54 and $p$-value is 0.131 . This result shows that there is no statistically significant difference between the two genders across the achievement variable.

It has been mentioned at the outset that this study used the tripartite model of measuring attitude. Thus, the two components (achievement and innovation) have other three sub-categories each: affect, behaviour (conation) and cognition. Therefore, the achievement variable was again seen across these categories in relation to gender.

Table 6: Cross-tabulation of achievement-affect by gender 
A. i.) Gender differences and achievement - affect

\begin{tabular}{|l|r|r|r|r|r|r|}
\hline \multirow{2}{*}{$\begin{array}{l}\text { Achievement- } \\
\text { affect score }\end{array}$} & \multicolumn{2}{|c|}{ Male } & \multicolumn{2}{c|}{ Female } & \multicolumn{2}{|c|}{ Total } \\
\cline { 2 - 7 } & Size & Percent & Size & Percent & Size & Percent \\
\hline Low & 4 & 13.8 & 1 & 4.8 & $\mathbf{5}$ & $\mathbf{1 0}$ \\
\hline High & 25 & 86.2 & 20 & 95.2 & $\mathbf{4 5}$ & $\mathbf{9 0}$ \\
\hline \multicolumn{1}{|c|}{ Total } & $\mathbf{2 9}$ & $\mathbf{5 8}$ & $\mathbf{2 1}$ & $\mathbf{4 2}$ & $\mathbf{5 0}$ & $\mathbf{1 0 0}$ \\
\hline
\end{tabular}

Source: Survey data

Proportionally comparing the data in the above table, $86.2 \%$ of males have high score on the variable under consideration while $95.2 \%$ of females scored high. Low scores on achievement affect are by $13.8 \%$ of male and $4.8 \%$ of female respondents. The mean difference of -0.89 was tested by a t-test and the result shows t-value of -1.81 and p-value of 0.076 . This result is slightly statistically significant, showing that female respondents tend to have higher achievement-affect compared to their male counterparts.

\section{A. ii.) Gender differences and achievement behaviour (conation)}

This sub-section tries to compare the respondents' entrepreneurial attitude as measured by achievement behaviour by gender.

Table 7: Gender and scores of achievement behaviour

\begin{tabular}{|l|r|r|r|r|r|r|}
\hline $\begin{array}{l}\text { Achievement- } \\
\text { behaviour } \\
\text { scores }\end{array}$ & \multicolumn{2}{|c|}{ Male } & \multicolumn{2}{c|}{ Female } & \multicolumn{2}{c|}{ Total } \\
\cline { 2 - 7 } & Size & Percent & Size & Percent & Size & Percent \\
\hline Low & 12 & 41.4 & 5 & 23.8 & $\mathbf{1 7}$ & $\mathbf{3 4}$ \\
\hline High & 17 & 58.6 & 16 & 76.2 & $\mathbf{3 3}$ & $\mathbf{6 6}$ \\
\hline \multicolumn{1}{|c|}{ Total } & $\mathbf{2 9}$ & $\mathbf{5 8}$ & $\mathbf{2 1}$ & $\mathbf{4 2}$ & $\mathbf{5 0}$ & $\mathbf{1 0 0}$ \\
\hline
\end{tabular}

Source: Survey data

When the data in Table 7 above is proportionally compared, $58.6 \%$ of males and $76.2 \%$ females have scored high, while it is $41.4 \%$ of males and $23.8 \%$ of females who scored low. The t-test result of gender by achievement-behaviour is -1.62 with p-value 
of 0.112 for a mean difference of -1.12 . This result is statistically is not significant.

A. iii) Gender differences and achievement - cognition

In Table 9 below, the cross tabulation between gender and achievement cognition is presented.

Table 8: Gender and achievement-cognition scores

\begin{tabular}{|l|r|r|r|r|r|r|}
\hline $\begin{array}{l}\text { Achievement- } \\
\begin{array}{l}\text { cognition } \\
\text { Scores }\end{array}\end{array}$ & \multicolumn{2}{|c|}{ Male } & \multicolumn{2}{c|}{ Female } & \multicolumn{2}{c|}{ Total } \\
\cline { 2 - 7 } & Size & Percent & Size & Percent & Size & Percent \\
\hline Low & 4 & 13.8 & 2 & 9.5 & $\mathbf{6}$ & $\mathbf{1 2}$ \\
\hline High & 25 & 86.2 & 19 & 90.5 & $\mathbf{4 4}$ & $\mathbf{8 8}$ \\
\hline \multicolumn{1}{|c|}{ Total } & $\mathbf{2 9}$ & $\mathbf{5 8}$ & $\mathbf{2 1}$ & $\mathbf{4 2}$ & $\mathbf{5 0}$ & $\mathbf{1 0 0}$ \\
\hline
\end{tabular}

\section{Source: Survey data}

When the proportional comparison between the sexes is observed, $86.2 \%$ of males and $90.5 \%$ of the females scored high, while $13.8 \%$ of males and $9.5 \%$ of females scored low.

For this variable, the mean difference between males and females is -0.10 , t-value is -0.17 and $p$-value is 0.869 , which is statistically non-significant.

In conclusion, in all the three sub-components of achievement, females have relatively higher scores than their male counterparts. However, it is only in the case of achievement- affect that there is slight statistical significance of the mean differences.

\section{B) Gender differences and innovation}

The second component that is used in this study to measure entrepreneurial attitude is innovation. This variable was crosstabulated against gender as shown in Table 10 below. 
Table 9: Cross-tabulation of gender by innovation scores

\begin{tabular}{|l|r|r|r|r|r|r|}
\hline \multirow{2}{*}{$\begin{array}{l}\text { Innovation } \\
\text { scores }\end{array}$} & \multicolumn{2}{|c|}{ Male } & \multicolumn{2}{c|}{ Female } & \multicolumn{2}{c|}{ Total } \\
\cline { 2 - 7 } & Size & Percent & Size & Percent & Size & Percent \\
\hline Low & 15 & 51.7 & 11 & 52.4 & $\mathbf{2 6}$ & $\mathbf{5 2}$ \\
\hline High & 14 & 48.3 & 10 & 47.6 & $\mathbf{2 4}$ & $\mathbf{4 8}$ \\
\hline \multicolumn{1}{|c|}{ Total } & $\mathbf{2 9}$ & $\mathbf{5 8}$ & $\mathbf{2 1}$ & $\mathbf{4 2}$ & $\mathbf{5 0}$ & $\mathbf{1 0 0}$ \\
\hline
\end{tabular}

Source: Survey data

When this result is observed proportionally, $48.3 \%$ of males and $47.6 \%$ of females score high on entrepreneurial attitude as measured by innovativeness. Conversely, $51.7 \%$ of males and $52.4 \%$ of females have low score. This proportional distribution does not indicate any remarkable difference between the sexes. However, when a t-test is run for a mean difference of -0.07 , $t$ value is -0.04 and $p$-value is 0.966 . So, there is no statistically significant difference between the genders.

Innovation was also observed across the three components (the tripartite $\{\mathrm{ABC}\}$ model of entrepreneurial attitude); affect, behaviour, and cognition.

B. i.) Gender differences and innovation-affect

In this section, innovation-affect is cross tabulated against gender as shown below.

Table 10: Gender by innovation-affect scores

\begin{tabular}{|l|r|r|r|r|r|r|}
\hline Innovation- & \multicolumn{2}{|c|}{ Male } & \multicolumn{2}{c|}{ Female } & \multicolumn{2}{c|}{ Total } \\
\cline { 2 - 7 } affect scores & Size & Percent & Size & Percent & Size & Percent \\
\hline Low & 6 & 20.7 & 5 & 23.8 & $\mathbf{1 1}$ & $\mathbf{2 2}$ \\
\hline High & 23 & 79.3 & 16 & 76.2 & $\mathbf{3 9}$ & $\mathbf{7 8}$ \\
\hline \multicolumn{1}{|c|}{ Total } & $\mathbf{2 9}$ & $\mathbf{5 8}$ & $\mathbf{2 1}$ & $\mathbf{4 2}$ & $\mathbf{5 0}$ & $\mathbf{1 0 0}$ \\
\hline
\end{tabular}

Source: Survey data

Proportionally, it is $79.3 \%$ males and $76.2 \%$ of females who scored high. Conversely, $20.7 \%$ of males and $23.8 \%$ of females scored low. According to these percentages, male respondents have slightly higher scores with respect to innovation-affect compared to female respondents. The result of the t-test for mean 
differences of 0.23 is t-value of 0.37 and p-value of 0.715 , which shows no statistically significant difference between the genders.

B. ii.) Gender differences and innovation behaviour (conation)

Table 12 below shows a striking finding as the results tend to go to the opposite direction.

Table 11: Cross-tabulation between gender and innovationbehaviour

\begin{tabular}{|l|r|r|r|r|r|r|}
\hline $\begin{array}{l}\text { Innovation- } \\
\text { behaviour } \\
\text { scores }\end{array}$ & \multicolumn{2}{|c|}{ Male } & \multicolumn{2}{c|}{ Female } & \multicolumn{2}{c|}{ Total } \\
\cline { 2 - 7 } & Size & Percent & Size & Percent & Size & Percent \\
\hline Low & 23 & 79.3 & 17 & 81.0 & $\mathbf{4 0}$ & $\mathbf{8 0}$ \\
\hline High & 6 & 20.7 & 4 & 19.0 & $\mathbf{1 0}$ & $\mathbf{2 0}$ \\
\hline \multicolumn{1}{|c|}{ Total } & $\mathbf{2 9}$ & $\mathbf{5 8}$ & $\mathbf{2 1}$ & $\mathbf{4 2}$ & $\mathbf{5 0}$ & $\mathbf{1 0 0}$ \\
\hline
\end{tabular}

Source: Survey data

Proportionally calculated, $20.7 \%$ of males and $19.0 \%$ of females scored high while $79.3 \%$ of males and $81.0 \%$ of females scored low with regard to innovation-behaviour. These results do not show remarkable differences by gender. But it is observed that both males and females have lower innovative-behaviour, with mean difference of $-0.38 \mathrm{t}$-value of -0.57 and $\mathrm{p}$-value of 0.574 . This result is statistically insignificant.

B. iii.) Gender differences and innovation-cognition

The third component in measuring innovation is cognition. The results of innovation- cognition are presented in the cross tabulation below.

Table 12: Gender and scores on innovation-cognition

\begin{tabular}{|l|r|r|r|r|r|r|}
\hline $\begin{array}{l}\text { Innovation- } \\
\begin{array}{l}\text { cognition } \\
\text { scores }\end{array}\end{array}$ & \multicolumn{2}{|c|}{ Male } & \multicolumn{2}{c|}{ Female } & \multicolumn{2}{c|}{ Total } \\
\cline { 2 - 7 } & Size & Percent & Size & Percent & Size & Percent \\
\hline Low & 7 & 24.1 & 5 & 23.8 & $\mathbf{1 2}$ & $\mathbf{2 4}$ \\
\hline High & 22 & 75.0 & 16 & 76.2 & $\mathbf{3 8}$ & $\mathbf{7 6}$ \\
\hline \multicolumn{1}{|c|}{ Total } & $\mathbf{2 9}$ & $\mathbf{5 8}$ & $\mathbf{2 1}$ & $\mathbf{4 2}$ & $\mathbf{5 0}$ & $\mathbf{1 0 0}$ \\
\hline
\end{tabular}

Source: Survey data 
Proportionally calculated, $75.0 \%$ of males and $76.2 \%$ of females scored high, while $24.1 \%$ of males and $23.8 \%$ of females scored low in innovation-cognition. The percentages do not show gender differences in entrepreneurial attitude with respect to innovationcognition, and the t-test also proves the statistical nonsignificance for the mean difference of 0.04 , as t-value is 0.07 and p-value is 0.944 .

\section{Gender differences and business success}

Gender differences vis-à-vis business success of the respondents were observed and are presented in the cross tabulation below.

Table 13: Cross-tabulation of gender and business success

\begin{tabular}{|l|r|r|r|r|r|r|}
\hline \multirow{2}{*}{$\begin{array}{l}\text { Business } \\
\text { Success }\end{array}$} & \multicolumn{2}{|c|}{ Male } & \multicolumn{2}{c|}{ Female } & \multicolumn{2}{|c|}{ Total } \\
\cline { 2 - 7 } & Size & Percent & Size & Percent & Size & Percent \\
\hline Bad & 0 & -- & 0 & -- & $\mathbf{0}$ & -- \\
\hline Low & 3 & 11.1 & 2 & 10.0 & $\mathbf{5}$ & $\mathbf{1 0 . 6}$ \\
\hline Good & 18 & 66.7 & 14 & 70.0 & $\mathbf{3 2}$ & $\mathbf{6 8 . 1}$ \\
\hline $\begin{array}{l}\text { Very } \\
\text { good }\end{array}$ & 6 & 22.2 & 4 & 20.0 & $\mathbf{1 0}$ & $\mathbf{2 1 . 3}$ \\
\hline \multicolumn{1}{|c|}{ Total } & $\mathbf{2 9}$ & $\mathbf{5 8}$ & $\mathbf{2 1}$ & $\mathbf{4 2}$ & $\mathbf{5 0}$ & $\mathbf{1 0 0}$ \\
\hline
\end{tabular}

\section{Source: Survey data}

Proportionally calculated, $22.2 \%$ of males and $20 \%$ of females reported their business' success to be very high ( $>=75 \%$ ), $66.7 \%$ of males and $70.0 \%$ of females reported their success to be good (50-74\%), and $11.1 \%$ of males and $10 \%$ of females responded that their success is low $(40-50 \%)$. No respondent reported their business success to be bad $(<40 \%)$. The percentages with respect to both sexes are close to each other and hence gender differences are not observed. The mean difference between the male and the female respondents is 0.01 , t-value is 0.07 and p-value is 0.947 . This shows that the difference is statistically non-significant. 


\section{Summary and discussions}

This study is more of indicative than conclusive because the number of respondents who filled out the questionnaire was limited.

- This study found out that there is moderate relationship $(\mathrm{r}=$ 0.24 ) between entrepreneurial attitude and business success. Similar ideas were reported by Reimers-Hild, et al (2005) and CAFRAD (2000), where there is relationship between entrepreneurial personality like need for achievement and innovation, and business success.

- Even though the percentages on overall entrepreneurial attitude scores show a $12.8 \%$ difference between the genders (71.4\% of females and $58.6 \%$ of males scores), the t-test that was run to see mean differences between the two genders (mean score of -2.17) proved to be statistically nonsignificant. This finding is consistent with Mueller (2004) and Brandstatter (1997) who found no statistically significant difference between the sexes. In contrast, however, James, et al (2004) found women university presidents to be more entrepreneurial than male presidents.

- Achievement-orientation was one of the variables used in measuring entrepreneurial attitude. Gender differences in relation to this exists where $100 \%$ of the female respondents were observed to be achievement-oriented than males (75.9\%). This $24.1 \%$ difference in achievement scores was, however, found to be statistically non-significant. The only slight statistical significance observed was when gender was observed against the variable of achievement-affect. Similarly, Routamaa, et al (2004) found the women in their sample to be more persistent in achieving their goals. Reimers-Hild et al. (2005), Lindsay (2005) and Koh (1996) said that $n$ Ach (need for achievement) is a key entrepreneurial trait and leads to entrepreneurial behaviour. James et al (2004) also affirmed university presidents to have show more observable behaviours related to entrepreneurial 
achievement (like transformational and change and improvement-oriented) than male university presidents.

- Gender differences with respect to innovation did not exist as $48.3 \%$ of males and $47.6 \%$ of females scored high. This is also true of all the three factors of innovation; namely affect, behaviour and cognition. The t-test results showed no statistical significance. CAFRAD (2000), Reimers-Hild (2005), and Mueller (2004), however, stated that innovativeness is an important variable in measuring entrepreneurial attitude.

- A different finding of this study is that compared to achievement scores, both male and female respondents of this study scored low in innovation, especially the innovationbehaviour variable. This result can be related to the culture where people seemed to copy what exists rather than creating new ways of running their business.

- Gender differences with respect to business success do not exist as the percentages that fell into the four rating categories were closely similar between males and females. Nor is the ttest result for the mean difference between the two genders statistically significant.

\section{Recommendation}

- This study shows that both male and female respondents have lower scores with respect to innovativeness, especially when measured by innovation-behaviour. Innovativeness is an important element in entrepreneurship. Therefore, in specific terms, those who train pharmacists and druggists should involve concepts on entrepreneurship with particular emphasis on innovativeness. Considering the larger society, Ethiopian business culture must be transformed to involve creativity and this is the responsibility of trainers in formal, non-formal and informal educational avenues. Policy-makers and responsible personnel in Chamber of Commerce must involve in translating this into effect. 
- This study shows that compared to their male counterparts, females have higher scores on entrepreneurial achievement. This is particularly observed on the achievement-affect variable. This indicates that the female respondents in this study have better entrepreneurial attitude, which, in turn, is the cause for entrepreneurial behaviour. So, policy makers, government officials and the society at large should support women to involve in such productive (bread winning) roles than confining themselves in reproductive jobs only. This allows women to help their society benefit more from their contributions.

- This study shows that entrepreneurial attitude and business success have moderate relationship. This asserts that high entrepreneurial attitude leads to success in business ventures. So, people in the business arena must work hard in developing entrepreneurial qualities through different kinds of trainings, which, in turn facilitate their success, which again have personal and societal benefits.

\section{References}


African Training and Research Centre in Administration for Development (CAFRAD) 2000. Towards an Innovative and Entrepreneurial Economy for Africa, Tangier, Morocco. Available at http://unpan1.un.org/intradoc/groups/public/documents/C AFRAD/UNPAN006k/9.pdf

Brandsttater, H. 1997. Becoming an entrepreneur - a question of personality structure? Journal of Economic Psychology, 18: $157-177$

Federal Democratic Republic of Ethiopia Ministry of Health (FDRE, MOH). 2004. Health and Health Related Indicators. Addis Ababa, Ethiopia.

Habtamu Wondimu. 1995. Dominant Values and Parenting Styles: Major Limiting Factors on the Development of Entrepreneurship in Ethiopia. In Ayalew Zegeye and HabteSelassie Hagos (Eds). Proceedings of the First Annual Conference on Management in Ethiopia, Addis Ababa University

James L. F., James V. K., Alice R. M. 2004. Entrepreneurial Women. Available at: http://europa.eu.int/comm/enterprise/enterprise_policy/sur vey/eurobarometer83.htm Accessed on 30 August 2005.

Koh, H.C. 1996. Testing hypothesis of entrepreneurial characteristics: A study of Hong Kong MBA students, Journal of Managerial Psychology, vol. 11, No. 3. Available at: http://www.ugurzel.com/liderlik/ingilizce/TESTING_HY POTHESES OF ENTREPRENEURIAL.htm Accessed on 18December 2006.

Lindsay, N. J. 2005. Toward a Cultural Model of Indigenous Entrepreneurial Attitude, Available at: http://www.vancouver.wsu.edu/amsrev/theory/lindsay 05-2005.html. Accessed on 24 August 2005

Mueller, S. L. 2004. Gender Gaps in Potential for Entrepreneurship across Countries and Cultures: Journal 
of Developmental Entrepreneurship. Available at:

http://www.findarticles.com/p/articles/mi_qa3906/is_2004 /2/ai_n10298123 Accessed on 30 August 2005.

Reimers-Hild C., King J. W., Foster J.E., Fritz S.M., Waller S.S., and Wheeler, D.W. 2005. A Framework for the "Entrepreneurial" Learner of the 21st Century, Available at:

http://www.westga.edu/ distance/ojdla/summer82/hild82. htm Accessed on 30 August 2005.

Robinson P.B., Stimpson D.V., Huefner J.C., and Hunt H..K. 1991. An Attitude Approach to the Prediction of Entrepreneurship. Entrepreneurship: Theory \& Practice, Vol. 15, Issue 4: 13 - 31

Routamaa, V., Hautala, T. and Rissanen, A-L. 2004. Hunting for Female Entrepreneurs Entrepreneurial Capacity and Gender, Available at:

http://www.sbaer.uca.edu/research/icsb/2004/papers pdf/105.pdf Accessed on 18 December, 2006. 